OPEN ACCESS

Edited by:

Carmen Fenoll,

University of Castilla-La Mancha,

Spain

Reviewed by:

Zakira Naureen,

University of Nizwa, Oman

Leslie Ann Weston,

Charles Sturt University, Australia

${ }^{*}$ Correspondence:

Rensen Zeng

rszeng@fafu.edu.cn; rensenzeng@163.com

Specialty section:

This article was submitted to Plant Biotic Interactions, a section of the journal Frontiers in Plant Science

Received: 26 June 2016 Accepted: 05 January 2017 Published: 23 January 2017

Citation: Wu X, Yu Y, Baerson SR, Song Y, Liang G, Ding C, Niu J, Pan Z and Zeng $R$ (2017) Interactions between Nitrogen and Silicon in Rice and Their Effects on Resistance toward the Brown Planthopper Nilaparvata lugens. Front. Plant Sci. 8:28. doi: 10.3389/fpls.2017.00028

\section{Interactions between Nitrogen and Silicon in Rice and Their Effects on Resistance toward the Brown Planthopper Nilaparvata lugens}

\author{
Xiaoying $W u^{1,2}$, Yaoguang Yu' ${ }^{1}$, Scott R. Baerson ${ }^{3}$, Yuanyuan Song ${ }^{1,2}$, Guohua Liang ${ }^{1}$, \\ Chaohui Ding ${ }^{1}$, Jinbo Niu', Zhiqiang Pan ${ }^{3}$ and Rensen Zeng ${ }^{2 *}$
}

1 State Key Laboratory of Conservation and Utilization of Subtropical Agro-Bioresources, College of Natural Resources and Environment, South China Agricultural University (SCAU), Guangzhou, China, ${ }^{2}$ Key Laboratory of Ministry of Education for Genetics, Breeding and Multiple Utilization of Crops, College of Crop Science, Fujian Agriculture and Forestry University, Fuzhou, China, ${ }^{3}$ Natural Products Utilization Research Unit, United States Department of Agriculture - Agricultural Research Service, Starkville, MS, USA

Nitrogen $(\mathrm{N})$ and silicon (Si) are two important nutritional elements required for plant growth, and both impact host plant resistance toward insect herbivores. The interaction between the two elements may therefore play a significant role in determining host plant resistance. We investigated this interaction in rice (Oryza sativa L.) and its effect on resistance to the herbivore brown planthopper Nilaparvata lugens (BPH). Our results indicate that high-level $(5.76 \mathrm{mM}) \mathrm{N}$ fertilization reduced $\mathrm{Si}$ accumulation in rice leaves, and furthermore, this decrease was likely due to decreased expression of $\mathrm{Si}$ transporters OsLsi1 and OsLsi2. Conversely, reduced N accumulation was observed at high $\mathrm{N}$ fertilization levels when $\mathrm{Si}$ was exogenously provided, and this was associated with down-regulation of OsAMT1;1 and OsGS1;1, which are involved in ammonium uptake and assimilation, respectively. Under lower $\mathrm{N}$ fertilization levels $(0.72$ and/or $1.44 \mathrm{mM})$, Si amendment resulted in increased OsNRT1:1, OsGS2, OsFd-GOGAT, OsNADH-GOGAT2, and OsGDH2 expression. Additionally, bioassays revealed that high $\mathrm{N}$ fertilization level significantly decreased rice resistance to $\mathrm{BPH}$, and the opposite effect was observed when Si was provided. These results provide additional insight into the antagonistic interaction between $\mathrm{Si}$ and $\mathrm{N}$ accumulation in rice, and the effects on plant growth and susceptibility to herbivores.

Keywords: nitrogen, silicon, interaction, rice, brown planthopper, growth-defense tradeoff

\section{INTRODUCTION}

Many studies have shown that plant anti-herbivore resistance is directly linked to physiological status, thus any factors affecting a plant's physiology could potentially alter its resistance to insect pests (Slansky, 1990; Altieri and Nicholls, 2003). Application of synthetic fertilizers alters the balance of nutrients and promotes crop growth, yet also alters the production of defense-related secondary compounds that can impact the susceptibility of a given crop to insect herbivores (Altieri and Nicholls, 2003). 
The macronutrient nitrogen $(\mathrm{N})$ is an essential element for growth and reproduction of both plants and animals, and has been considered critical for determining interactions between plants and their consumers, including herbivorous insects (Chen et al., 2008). Nitrogen is the most frequently used fertilizer component in crop production, and can also exert an array of bottom-up effects on herbivore populations and their natural enemies (Chen et al., 2010; Winter and Rostás, 2010).

The acquisition and effective utilization of $\mathrm{N}$ from host plants is key to the growth and development of most herbivorous insect species, and host plant $\mathrm{N}$ levels can be the most important factor affecting herbivore performance (Awmack and Leather, 2002). Numerous studies have shown that high-level $\mathrm{N}$ fertilizer application to crops can influence plant-insect interactions, and potentially increase growth, food consumption, survival, reproductive rates and population densities of insect herbivores (Mattson, 1980; Moon et al., 1995; Brodbeck et al., 2001; Khan and Port, 2008). Conversely, a deficiency of $\mathrm{N}$ may alter plant metabolism and trigger insect resistance (Comadira et al., 2015). It has been demonstrated that the increasing populations of major insect pests of rice, including planthoppers, leaffolders, and stem borers, are closely related to the long-term excessive application of $\mathrm{N}$ fertilizers in most of the rice growing areas in Asia (Lu et al., 2007).

Silicon ( $\mathrm{Si}$ ) is the second most abundant element in soil and accumulates to significant levels within the cells of many plant species. Although the physiological role of plant-assimilated Si has long been debated, its beneficial effects on plant resistance to both abiotic and biotic stresses, including insect herbivory, is well established (e.g., Reynolds et al., 2009; Meharg and Meharg, 2015). Two different mechanisms have been proposed to account for Si-mediated plant defense against insect herbivores. One mechanism involves amorphous Si depositing in plant tissues acting as a physical barrier, leading to increased rigidity and abrasiveness of plant tissues, thus reducing its digestibility to insect pests (Keeping and Meyer, 2006; Massey and Hartley, 2009). A second mechanism involves the ability of Si taken up from the soil solution by plant roots to induce specific plant chemical defenses and prime phytohormone-mediated defense responses via the jasmonate (JA) signaling pathway (Fawe et al., 1998; Gomes et al., 2005; Fauteux et al., 2006; Ye et al., 2013), which may include the increased release of plant volatiles which attract natural enemies of insect herbivores (Kvedaras et al., 2010).

Currently available evidence indicates that, in specific plant species, $\mathrm{Si}$ accumulation increases plant resistance against insect herbivores, while high $\mathrm{N}$ levels are associated with increased insect pest population densities. Thus, for Si-accumulating plant species, there appears to be tradeoff between $\mathrm{Si}$ and $\mathrm{N}$ accumulation with significant consequences for a plant's ability to mount defenses against insect herbivores. In rice plants, external $\mathrm{N}$ application can reduce intracellular $\mathrm{Si}$ accumulation, which was associated by one study with a decline in Si deposition in the epidermal cell walls of leaves (Mauad et al., 2003; Tsujimoto et al., 2014). Additionally, in an earlier study working with rice seedlings it was found that $\mathrm{Si}$ amendment in organic soil resulted in decreased plant $\mathrm{N}$ contents (Deren, 1997). Although prior studies have shown that there is an interaction between $\mathrm{N}$ and $\mathrm{Si}$ uptake in plants (see also Massey et al., 2007; Lemus et al., 2008), the mechanistic basis for this interaction and its relationship to insect herbivore performance have not been directly examined.

Rice (Oryza sativa L.) is an important crop as well as a high Si-accumulating plant, with reported Si contents reaching levels as high as $10 \%$ of total shoot dry weight (Epstein, 1999; Ma and Yamaji, 2006). The brown planthopper (BPH), Nilaparvata lugens Stål (Homoptera: Delphacidae), is a phloem-feeding insect and one of the most economically deleterious insect pests of cultivated rice (Bottrell and Schoenly, 2012). It was previously shown that high $\mathrm{N}$ fertilization levels in rice increased survival, fecundity, and egg hatchability of BPH nymphs and adults (Lu et al., 2005), whereas silicon application enhanced rice resistance against BPH (He et al., 2015). Thus, the rice-BPH interaction represents an excellent model for further examining relationships between $\mathrm{N}$ uptake, Si uptake, and resistance to insect herbivores in Siaccumulating plants. In the present work, we firstly investigate the molecular mechanisms involved in the interactions between $\mathrm{N}$ and $\mathrm{Si}$ in rice plants and their effects on $\mathrm{BPH}$ performance, by examining the transcriptional responses of a panel of genes involved in $\mathrm{Si}$ and $\mathrm{N}$ transport and assimilation, under various fertilization regimes (two Si and three $\mathrm{N}$ concentrations), and in the presence and absence of $\mathrm{BPH}$ infestation. Our finding would provide further evidence to understand the molecular details of the interaction between $\mathrm{Si}$ and $\mathrm{N}$ in rice.

\section{MATERIALS AND METHODS}

\section{Plant Material and BHP Insects}

Rice (Oryza sativa L. cv. Shishoubaimao), was used for this study. BPH [Nilaparvata lugens (Stål)] was originally obtained from rice fields on the campus of South China Agricultural University in Guangzhou, China, and maintained on rice plants in a greenhouse.

\section{Plant Growth and Treatment}

Rice seeds were surface-sterilized with $10 \%$ (v/v) $\mathrm{H}_{2} \mathrm{O}_{2}$ for $10 \mathrm{~min}$, rinsed with distilled water three times, then pre-imbibed in distilled water for 1 day. After pre-germination for 2 days at $28^{\circ} \mathrm{C}$, seeds were transferred to culture dishes containing vermiculite and $0.5 \times$ modified Kimura $B$ nutrient solution, and maintained in a growth chamber for 10 days. Thereafter, three plants were transplanted to a plastic box containing $1.2 \mathrm{~L} 0.5 \times$ modified Kimura B nutrient solution. After 7 additional days rice plants of uniform size were exposed to different levels of $\mathrm{N}$ and $\mathrm{Si}$.

\section{$\mathrm{N}$ treatment}

Uniformly staged rice plants (described above) were transferred to $1 \times$ modified Kimura B nutrient solution without nitrogen. Nutrient solutions were then amended with three different $\mathrm{N}$ levels: (a) N-limited level: $0.72 \mathrm{mM}$; (b) basal/medium level: $1.44 \mathrm{mM}$; (c) high level, $5.76 \mathrm{mM}$. The nitrogen source used was an equimolar mixture of $\left(\mathrm{NH}_{4}\right)_{2} \mathrm{SO}_{4}$ and $\mathrm{Ca}\left(\mathrm{NO}_{3}\right)_{2} \cdot 4 \mathrm{H}_{2} \mathrm{O}$. $\mathrm{CaCl}_{2}$ was also added as needed to balance the calcium levels in the different treatment solutions. 


\section{Si Treatment}

Sodium silicate $\left(\mathrm{Na}_{2} \mathrm{SiO}_{3} \cdot 9 \mathrm{H}_{2} \mathrm{O}, 1.5 \mathrm{mM}\right)$ was also added to the above nutrient solution at different $\mathrm{N}$ levels. For Siuntreated plants, $\mathrm{NaCl}$ was also added to balance sodium levels. All treated rice plants were grown in a greenhouse with day/night temperature of $30^{\circ} \mathrm{C} / 26^{\circ} \mathrm{C}, 75 \%$ relative humidity and nature daylight. The modified Kimura $\mathrm{B}$ nutrient solution consisted of macronutrients: $0.36 \mathrm{mM}\left(\mathrm{NH}_{4}\right)_{2} \mathrm{SO}_{4}, 0.36 \mathrm{mM}$ $\mathrm{Ca}\left(\mathrm{NO}_{3}\right)_{2} \cdot 4 \mathrm{H}_{2} \mathrm{O}, 0.27 \mathrm{mM} \mathrm{K} \mathrm{SO}_{4}, 0.55 \mathrm{mM} \mathrm{MgSO} \cdot \cdot 7 \mathrm{H}_{2} \mathrm{O}$, $0.18 \mathrm{mM} \mathrm{KH} \mathrm{KO}_{4}$; and micronutrients: $20 \mu \mathrm{M}$ EDTA-Fe, $0.77 \mu \mathrm{M} \mathrm{ZnSO}_{4} \cdot 7 \mathrm{H}_{2} \mathrm{O}, 0.32 \mu \mathrm{M} \mathrm{CuSO}_{4} \cdot 5 \mathrm{H}_{2} \mathrm{O}, 46.26 \mu \mathrm{M}$ $\mathrm{H}_{3} \mathrm{BO}_{3}, 9.10 \mu \mathrm{M} \mathrm{MnCl}_{2}, 0.15 \mu \mathrm{M}\left(\mathrm{NH}_{4}\right)_{6} \mathrm{Mo}_{7} \mathrm{O}_{24} \cdot 4 \mathrm{H}_{2} \mathrm{O}$. Nutrient solutions were replenished every 3 days during the experiment. After 30 days the rice plants grown at different $\mathrm{N}$ levels, with or without Si amendment, were harvested and used for follow up analyses (described below).

\section{Rice Dry Weight}

Root and shoot systems of rice plants were harvested following exposure to the various nutrient treatment solutions (described above), dried at $70^{\circ} \mathrm{C}$ for 3 days, then weighed. Root/shoot ratios were then calculated from the dry weight values.

\section{Elemental Analysis}

For measurement of $\mathrm{N}$ and $\mathrm{Si}$ contents, leaves and stems of rice plants were first harvested following exposure to the various nutrient treatment solutions (described above), dried at $70^{\circ} \mathrm{C}$ for 3 days, then hand-pulverized to a fine powder using a mortar and pestle. Total $\mathrm{N}$ contents in $2 \mathrm{mg}$ dry samples were then analyzed using an Elemental Analyser (TOC select, Elementar, Germany). Total Si contents in $10 \mathrm{mg}$ dry samples were then analyzed by molybdenum blue colorimetric method developed by Novozamsky et al. (1984) with modifications described by Dannon and Wydra (2004). Plant materials were dissolved in the mixture of hydrogen chloride and hydrogen fluoride (1:2), and ammonium molybdate was added into the solution as color agent. Si content in the resulting solutions was detected at $811 \mathrm{~nm}$ by a spectrophotometer.

\section{BPH Bioassays}

Five emergent macropterous female BPH adults were starved for $2 \mathrm{~h}$, then placed into parafilm bags which were fastened directly onto the plant shoots. Total honeydew produced by each group was then weighed following a $48 \mathrm{~h}$ feeding period. At the same time, the number of dead BPH were counted to determine \% mortality values. Ten rice plants were used for each treatment, and the experiment was repeated twice. At 4 and $8 \mathrm{~h}$ after $\mathrm{BPH}$ infestation, the leaf sheathes were harvested for real-time PCR analysis of defense gene expression in BPH infested and un-infested rice plants.

\section{Quantitative Real-Time PCR Analysis}

Total RNAs were extracted from $0.1 \mathrm{~g}$ flash-frozen, powdered leaf /root samples using the TRIzol Reagent (Life Technologies, USA) according to the manufacturer's instructions. First-strand cDNAs were synthesized from $1 \mu \mathrm{g}$ of total RNA using a
M-MLV Reverse Transcripatase (ThermoFisher Scientific, USA) according to the manufacturer's instructions. Real-time PCR was performed using SYBR Premix Ex Taq II (Tli RNaseH Plus, Takara, Japan) with a 7500 Fast Real-Time PCR Sequence Detection System (Applied Biosystems 7500, USA). The thermal profile used was $90^{\circ} \mathrm{C}$ for $30 \mathrm{~s}$, followed by 40 cycles of $95^{\circ} \mathrm{C}$ for $15 \mathrm{~s}, 60^{\circ} \mathrm{C}$ for $30 \mathrm{~s}$, then $72^{\circ} \mathrm{C}$ for $30 \mathrm{~s}$. Melting curve analysis and agarose gel electrophoresis were carried out to verify amplicon specificity. Relative transcript levels were calculated using the double-standard curves method, and the rice housekeeping gene OsActin was used as an endogenous control. All of the genespecific primers used in this study are listed in Supplementary Table S1. All assays were performed in triplicate using three biological replicates per treatment.

\section{Data Analysis}

The SPSS statistics 17.0 package for windows was used for statistical analysis. Data were evaluated by factorial ANOVA with treatment differences among means tested at $P=0.05$ using a Tukey post hoc test.

\section{RESULTS}

\section{Effects of $\mathrm{N}$ and $\mathrm{Si}$ on Rice Biomass Accumulation}

In the absence of Si amendment, total dry weight values were significantly higher in plants provided with the high $(5.76 \mathrm{mM})$ $\mathrm{N}$ treatment in comparison with plants provided with the low $(0.72 \mathrm{mM}) \mathrm{N}$ treatment (3.8 g dry weight vs. $2.5 \mathrm{~g}$; Figure 1A). For plants provided with $\mathrm{Si}$ in addition to either 0.72 or $1.44 \mathrm{mM}$ $\mathrm{N}$, dry weight values were significantly higher in comparison with plants not provided with Si but receiving the same $\mathrm{N}$ treatments. This stimulatory effect of $\mathrm{Si}$ on biomass accumulation was not observed, however, when $5.76 \mathrm{mM}$ was provided (Figure 1A). Additionally, Si amendment led to significantly lower root/shoot ratios using the $0.72 \mathrm{mM} \mathrm{N}$ treatment relative to plants not provided with Si receiving the same $\mathrm{N}$ treatment (Figure 1B).

\section{Effects of N Fertilizer on Si Uptake and Translocation}

In rice plants not provided with $\mathrm{Si}$, there were no significant differences observed in leaf $\mathrm{Si}$ accumulation levels among the different $\mathrm{N}$ treatments (Figure 2A). Si amendment resulted in dramatically higher levels of $\mathrm{Si}$ accumulation in both leaves and stems for all $\mathrm{N}$ treatments (Figures 2A,B). Interestingly, in plants provided with $\mathrm{Si}, \mathrm{Si}$ contents were lower at the highest $\mathrm{N}$ treatment level $(5.76 \mathrm{mM})$ than the Si contents observed in plants provided with $0.72 \mathrm{mM} \mathrm{N}$ (Figure 2A). In addition, in the absence of added $\mathrm{Si}$, stems of $1.44 \mathrm{mM} \mathrm{N}$-fertilized plants had higher Si contents than stems of plants provided with either 0.72 or $5.76 \mathrm{mM} \mathrm{N}$ (Figure 2B).

OsLsi1, OsLsi2, and OsLsi6 represent the major transporters involved in the uptake and translocation of $\mathrm{Si}$ in rice plants (Ma and Yamaji, 2008; Yamaji et al., 2008). Real-time PCR analysis revealed that in Si-treated plants the steady-state transcript levels 

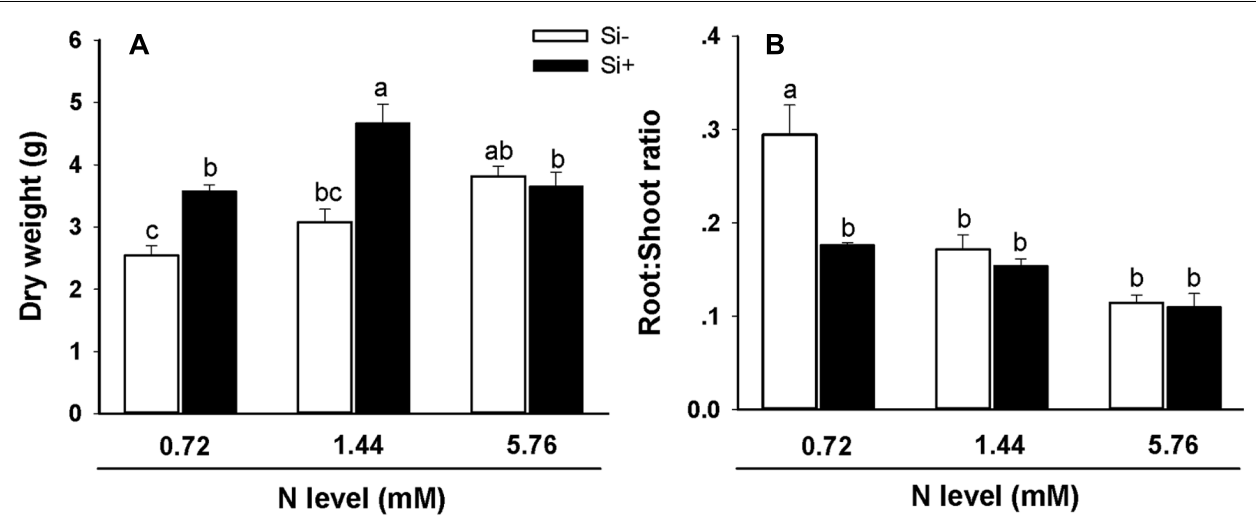

FIGURE 1 | Dry weight (A) and root/shoot ratios (B) of rice plants fertilized at different nitrogen (N) levels (0.72, 1.44 , and 5.76 mM) with or without silicon (Si) amendment $(\mathrm{Si}-, \mathrm{Si}+)$. Values are mean $\pm \mathrm{SE}(n=10)$. Letters above bars indicate significant differences among treatments $($ Tukey's multiple range test, $P<0.05)$.
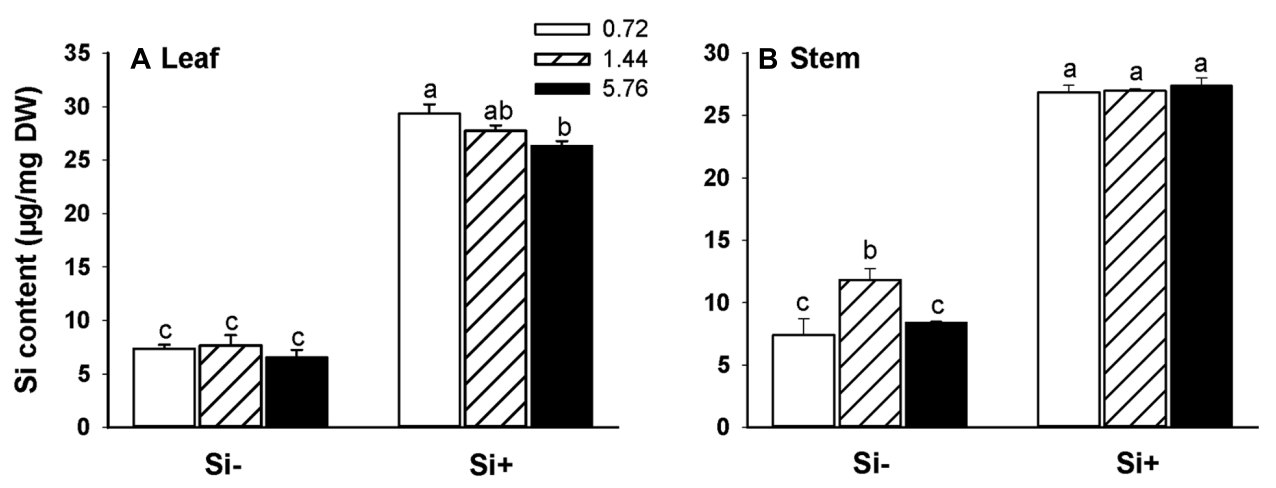

FIGURE 2 | Silicon (Si) contents of leaves (A) and stems (B) of rice plants fertilized at different N levels $(0.72,1.44$, and 5.76 mM), with or without Si amendment $(\mathrm{Si}-, \mathrm{Si}+)$. Values are mean $\pm \mathrm{SE}(n=6)$. Letters above bars indicate significant differences among treatments (Tukey's multiple range test, $P<0.05)$.

of OsLsi1 and OsLsi2 decreased as higher $\mathrm{N}$ fertilization levels were provided (Figures 3A,B). Plants not provided with Si also showed decreased OsLsi1 and OsLsi2 transcript levels at the highest $(5.76 \mathrm{mM}) \mathrm{N}$ fertilization rates in comparison with the 0.72 or $1.44 \mathrm{mM} \mathrm{N}$ treatments, however, the transcript levels for both genes were also somewhat higher in plants provided $1.44 \mathrm{mM} \mathrm{N}$ relative to plants provided with the $0.72 \mathrm{mM} \mathrm{N}$ treatment (Figures 3A,B). No significant changes in transcript accumulation levels were observed for OsLsi6 regardless of the treatment solution provided (Figure 3C).

\section{Effects of Si Treatment on N Uptake and Assimilation}

In both leaves and stems of rice, high $(5.76 \mathrm{mM})$ levels of $\mathrm{N}$ resulted in significantly increased $\mathrm{N}$ contents relative to plants provided with low $(0.72 \mathrm{mM}) \mathrm{N}$, irrespective of Si amendment (Figures 4A,B). However, the addition of Si resulted in decreased $\mathrm{N}$ contents in both leaves and stems for nearly all treatments, with the only exception being $\mathrm{N}$ content levels in $0.72 \mathrm{mM}$ $\mathrm{N}$-treated leaves (Figure 4A). In leaf tissues, Si amendment lowered $\mathrm{N}$ contents by $16 \%$ and $8 \%$ at $\mathrm{N}$ treatment levels of 1.44 and $5.76 \mathrm{mM}$, respectively, and in stem tissues, Si amendment lowered $\mathrm{N}$ contents by $26 \%, 19 \%$ and $9 \%$ at $\mathrm{N}$ treatment levels of $0.72,1.44$, and $5.76 \mathrm{mM}$, respectively (Figures 4A,B).

The steady-state transcript levels of a panel of genes critical for $\mathrm{N}$ uptake and assimilation in rice were also monitored via qRT-PCR for the different $\mathrm{N}$ treatment levels in the presence and absence of $\mathrm{Si}$ amendment (Figures 5A-H). For all three $\mathrm{N}$ treatments, $\mathrm{Si}$ amendment resulted in substantially reduced transcript levels for $\mathrm{NH}_{4}{ }^{+}$transporter OsAMT1;1 (Figure 5A). Furthermore, a similar trend was observed for transcripts of OsGS1;1, which encodes the enzyme glutamine synthase 1 that uses $\mathrm{NH}_{4}{ }^{+}$and glutamate to generate glutamine (Figure 5C). At the $0.72 \mathrm{mM} \mathrm{N}$ treatment level, Si amendment led to increased transcript levels for OsGS2, OsFd-GOGAT and OsNADH-GOGAT2 (Figures 5D-F). At the $1.44 \mathrm{mM} \mathrm{N}$ treatment level, Si amendment led to increased OsNRT1:1, OsFdGOGAT, OsNADH-GOGAT2, and OsGDH2 transcript levels (Figures 5B,E-G). At the highest $\mathrm{N}$ treatment level $(5.76 \mathrm{mM})$ $\mathrm{Si}$ amendment led to reduced transcript levels of OsNRT1:1 and $\mathrm{OsGDH} 2$ (Figures 5B,G), but had no discernible effect on transcript levels for the other four $\mathrm{N}$ metabolism-associated genes tested. In particular, the strong correlation observed between OsAMT1;1 and OsGS1;1 steady transcript levels with $\mathrm{N}$ accumulation levels in rice under various nutrient regimes 

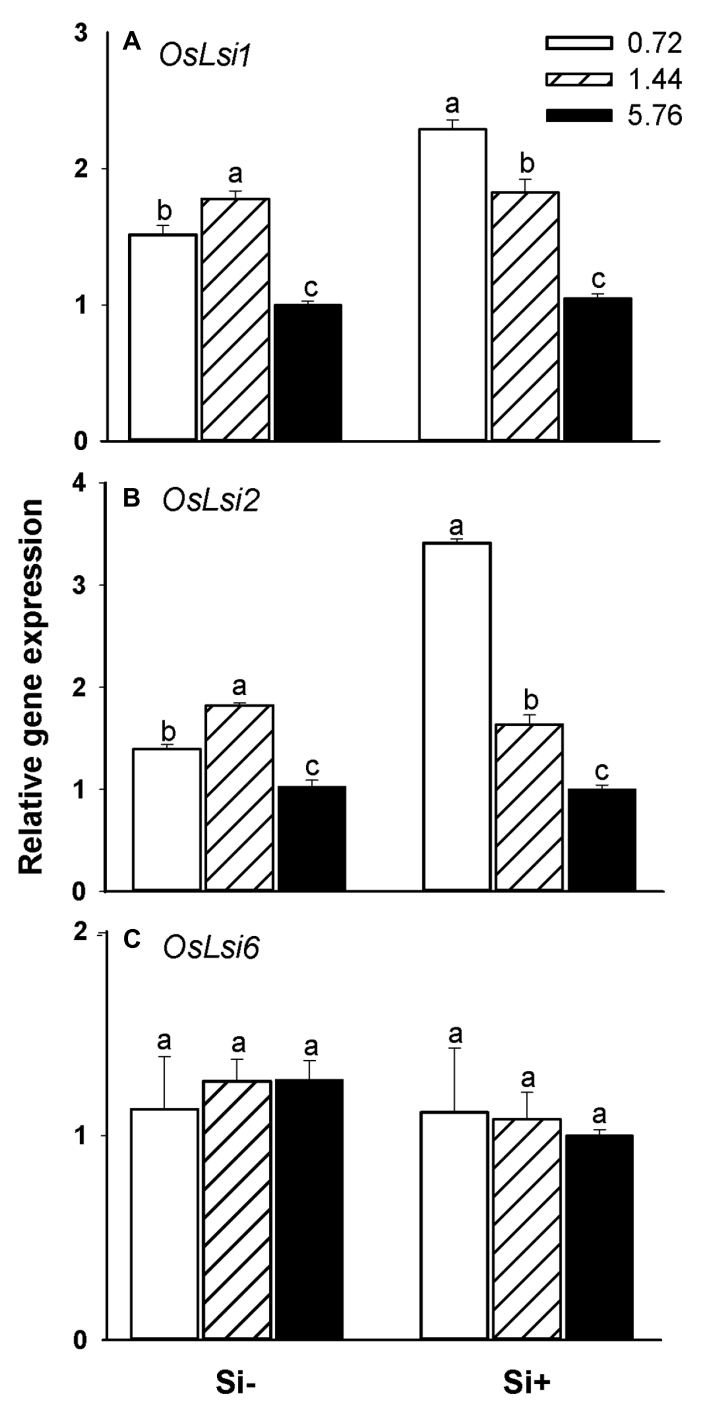

FIGURE 3 | Effects of different $\mathbf{N}$ fertilization levels on the relative expression of genes (A) OsLsi1, (B) OsLsi2, and (C) OsLsi6 involved in Si uptake and translocation in rice plants. Values are mean \pm SE $(n=3)$. Letters above bars indicate significant differences among treatments (Tukey's multiple range test, $P<0.05)$.

(Figure 4 vs. Figures 5A,C) strongly suggests that the observed decrease in $\mathrm{N}$ accumulation in plants provided with exogenous $\mathrm{Si}$ is due, at least in part, to decreased $\mathrm{NH}_{4}{ }^{+}$uptake via OsAMT1;1 and decreased $\mathrm{NH}_{4}{ }^{+}$assimilation via OsGS1;1.

\section{Effects of N Levels and Si Amendment on Rice Resistance to BPH}

Bioassays showed significantly increased $\mathrm{BPH}$ honeydew excretion (an indicator of food intake) for insects feeding on rice plants grown using the high $(5.76 \mathrm{mM}) \mathrm{N}$ treatment relative to insects feeding on plants provided with low $(0.72 \mathrm{mM}) \mathrm{N}$ without Si amendment (Figure 6A). However, when Si was also provided, honeydew excretion was reduced in comparison with insects feeding on plants not provided with Si receiving the same

$\mathrm{N}$ treatment. Interestingly, $\mathrm{BPH}$ mortality was unaffected by host plant $\mathrm{N}$ treatment regime $(0.72$ vs. 1.44 vs. $5.76 \mathrm{mM} \mathrm{N})$ on Si-untreated plants (Figure 6B). However, BPH feeding on plants fertilized with the high $(5.76 \mathrm{mM}) \mathrm{N}$ treatment solution amended with Si exhibited significantly higher percent mortality than insects feeding on plants not provided with Si (Figure 6B).

Non-expressor of PR genes1 (NPR1) is the central regulator in SA-mediated plant anti-herbivore defense (Wasternack and Hause, 2013). Real-time PCR analysis showed that Si amendment reduced OsNPR1 transcript levels in plants relative to levels observed in Si-untreated plants for all $\mathrm{N}$ fertilization levels tested without BPH (Figure 7A). BPH infestation led to significantly increased OsNPR1 transcript levels in both Si-treated and untreated plants at 4 and $8 \mathrm{~h}$ after $\mathrm{BPH}$ inoculation. Although transcript levels of OsNPR1 were not higher in Si-treated relative to Si-untreated plants at the two lower $\mathrm{N}$ fertilization levels $(0.72$ and $1.44 \mathrm{mM}$ ) at 4 and $8 \mathrm{~h}$ after $\mathrm{BPH}$ feeding, the magnitude of induction following $\mathrm{BPH}$ infestation was generally greater in Si-treated (by 2.76 and 3.73-fold for 0.72 and $1.44 \mathrm{mM}$ $\mathrm{N}$ level, respectively) versus untreated plants (by 1.94 and 2.94-fold for 0.72 and $1.44 \mathrm{mM} \mathrm{N}$ level, respectively) at $8 \mathrm{~h}$. Furthermore, in high $\mathrm{N}$-fertilized $(5.76 \mathrm{mM})$ plants, Si treatment significantly increased OsNPR1 transcript levels in response to $\mathrm{BPH}$ infestation after 4 or $8 \mathrm{~h}$ compared to Si-untreated plants, in both the steady-state transcript levels observed as well as the magnitude of induction (Figure 7A).

Mitogen-activated protein kinase (MAPK) cascades also play an important role in plant signaling pathways involved in antiherbivore defense responses (Pitzschke et al., 2009). Real-time PCR analyses revealed that Si treatment led to decreased OsMPK3 transcript levels in low $\mathrm{N}$-fertilized rice, but tended to increase the transcripts under high $\mathrm{N}$ fertilization (Figure 7B). Overall, Si-amendment did not appear to significantly affect OsMPK6 expression (Figure 7C). At $8 \mathrm{~h}$ post-BPH infestation, OsMPK3 and OsMPK6 transcript levels in both Si-treated and untreated plants were significantly induced by $\mathrm{BPH}$ infestation relative to non-BPH infested plants. In Si-untreated plants, OsMPK3 transcript levels were much higher under low $\mathrm{N}$ fertilization (0.72 and $1.44 \mathrm{mM}$ ) than transcript levels observed under high $\mathrm{N}$ fertilization $(5.76 \mathrm{mM})$ at 4 and $8 \mathrm{~h}$ post-BPH inoculation (Figure 7B), but this was not the case for OsMPK6 (Figure 7C). As was also the case for OsNPR1 transcript levels observed in plants receiving high $\mathrm{N}$ fertilization, $\mathrm{Si}$ treatment significantly increased OsMPK3 transcript levels, as well as the magnitude of induction observed relative to Si-untreated plants at 4 and $8 \mathrm{~h}$ post-BPH infestation (Figure 7B). In low $\mathrm{N}$ fertilization, the fold-change in OsMPK3 transcript levels in response to $\mathrm{BPH}$ infestation was also increased in Si-treated versus untreated plants after $\mathrm{BPH}$ inoculation at $8 \mathrm{~h}$.

\section{DISCUSSION}

Both nitrogen and silicon play an important role in rice resistance toward herbivorous insects. The application of fertilizer causes changes in plant nutrient status, which may in turn impact plant resistance levels against herbivores (De Kraker et al., 2000). 

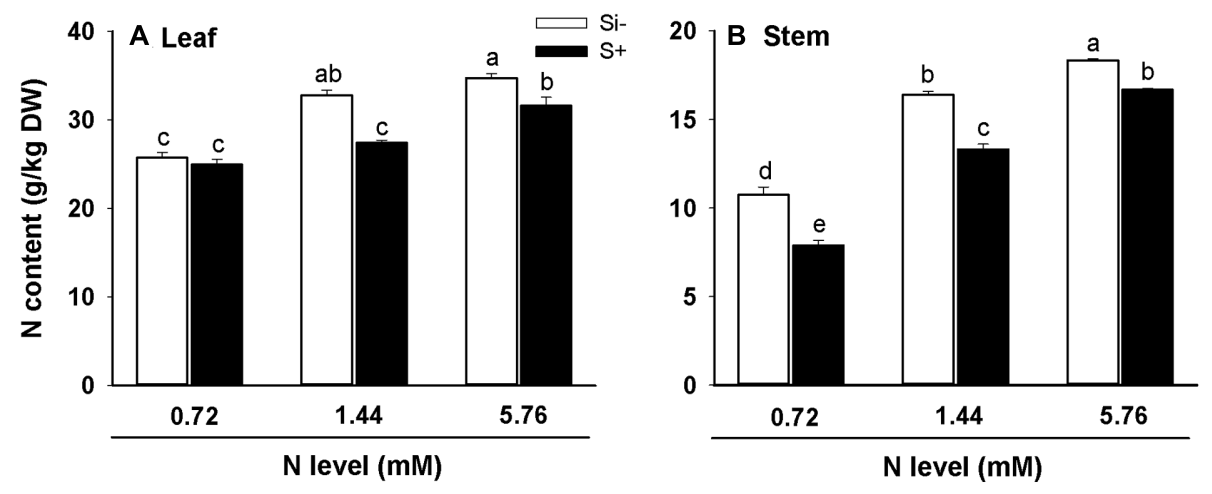

FIGURE 4 | Nitrogen contents of leaves (A) and stems (B) of rice plants fertilized at different N levels (0.72, 1.44, and 5.76 mM), with or without Si amendment $(\mathrm{Si}-, \mathrm{Si}+)$. Values are mean $\pm \mathrm{SE}(n=6)$. Letters above bars indicate significant differences among treatments (Tukey's multiple range test, $P<0.05)$.

In the present study, we found that high $\mathrm{N}$ fertilization levels significantly reduced the Si content in rice leaves (Figure 2A), consistent with observations made in previous studies (Massey et al., 2007; Mauad et al., 2013; Tsujimoto et al., 2014). To examine the molecular basis for this effect, we first monitored steady-state transcript levels of OsLsi1, OsLsi2, and OsLsi6 which are directly involved in $\mathrm{Si}$ uptake and translocation in rice, by qRT-PCR analysis. OsLsil and 2 are responsible for $\mathrm{Si}$ uptake in roots, and OsLsi6 is involved in the distribution of Si within shoot tissues. Both OsLsi1 and OsLsi6 belong to the nodulin-26 intrinsic protein III (NIP III) subgroup of aquaporins, while OsLsi2 is a secondary active anion transporter ( $\mathrm{Ma}$ and Yamaji, 2008; Yamaji et al., 2008). Importantly, we found that high $\mathrm{N}$ fertilization levels led to decreased OsLsi1 and OsLsi2 transcript levels (Figures 3A,B), but did not influence OsLsi6 expression (Figure 3C). The observed reduced accumulation of $\mathrm{Si}$ in leaves of rice provided with high levels of $\mathrm{N}$ (Figure 2A) is therefore likely attributable to decreased OsLsi1 and/or OsLsi2 activity under these conditions. In leaves of Si-untreated plants where Si contents were much lower, higher $\mathrm{N}$ fertilization levels did not significantly affect leaf Si contents (Figure 2A) even though OsLsi1 and OsLsi2 steady-state transcript levels were reduced by 34 and 26\%, respectively (Figures 3A,B) in plants provided with $5.76 \mathrm{mM} \mathrm{N}$ relative to plants provided with $0.72 \mathrm{mM}$ N. Additionally, OsLsi1 and OsLsi2 transcript levels were significantly higher in Si-untreated plants fertilized with $1.44 \mathrm{mM} \mathrm{N}$, compared with plants provided with $0.72 \mathrm{mM} \mathrm{N}$ (Figures 3A,B), and this corresponded with significantly higher stem Si contents under these nutrient conditions (Figure 2B). Differences in stem $\mathrm{Si}$ contents among plants provided with $\mathrm{Si}$ at various $\mathrm{N}$ levels were not observed. Taken together, the experimental results shown in Figures 2 and 3 suggest that increased $\mathrm{N}$ fertilization negatively impacts $\mathrm{Si}$ accumulation in rice plants via reduced OsLsi1 and OsLsi2 expression, and available Si levels as well as tissue-specific factors also influence these interactions.

The results obtained in the present work also provide further evidence for an antagonistic interaction occurring between $\mathrm{Si}$ and $\mathrm{N}$ uptake in rice, as Si-amendment to the treatment solutions significantly reduced $\mathrm{N}$ contents in both leaves and stems, irrespective of the $\mathrm{N}$ levels provided (Figures 4A,B). The only exception to this was leaf tissues fertilized with limited $(0.72 \mathrm{mM})$ $\mathrm{N}$, thus available $\mathrm{N}$ levels are also likely to play a role in this interaction. These results are in agreement with prior studies suggesting interference of plant N uptake by Si (e.g., Deren, 1997; Massey et al., 2007).

In addition to observed inhibitory effects of increasing $\mathrm{N}$ on the expression of genes required for Si uptake (Figures 3A,B), the present work also showed that exogenously-provided $\mathrm{Si}$ can in turn inhibit the expression of genes important for $\mathrm{N}$ uptake and assimilation in rice, thus providing some insight into the mechanism underlying this interaction (Figure 5). OsAMT1;1 and OsNRT1;1 are two of the major transporters involved in $\mathrm{NH}_{4}{ }^{+}$and $\mathrm{NO}_{3}{ }^{-}$uptake in rice, respectively, and glutamine synthetase (GS), glutamate synthase (Fd-GOGAT and NADH-GOGAT), glutamate dehydrogenase (GDH) and $\mathrm{NO}_{3}{ }^{-}$ reductase (NR) are responsible for $\mathrm{NH}_{4}{ }^{+}$or $\mathrm{NO}_{3}{ }^{-}$assimilation in plant $\mathrm{N}$ metabolism (Tabuchi et al., 2007; Rennenberg et al., 2010). Our results suggest that OsAMT1;1 and OsGS1;1 may play an important role in Si-mediated inhibition of $\mathrm{N}$ uptake and assimilation, since transcript levels for both genes were significantly reduced in Si-treated plants at all three $\mathrm{N}$ levels relative to Si-untreated plants (Figures 5A,C). Interestingly, at lower $(0.72$ and $1.44 \mathrm{mM}) \mathrm{N}$ fertilization levels, Si treatment tended to correlate with elevated OsNRT1;1, OsGS2, OsFdGOGAT, OsNADH-GOGAT2 and OsGDH2 transcript levels (Figures 5B,D-G), potentially identifying a feedback response mechanism operating under reduced $\mathrm{N}$ availability, which could also at least partially account for the observed increases in plant dry weight and decreases in root/shoot ratios under reduced N conditions (Figures 1A,B; see also Ericsson, 1995). In addition, fertilization at the highest $\mathrm{N}$ levels led to decreased OsNRT1;1 and OsGDH2 transcript levels (Figures 5B,G) which would presumably further reduce rates of $\mathrm{N}$ uptake and assimilation. Thus, the results further suggest that in rice $\mathrm{Si}$ amendment influences $\mathrm{N}$ uptake and assimilation rates differentially under conditions of low versus high $\mathrm{N}$. The present study as well as prior work clearly show that there is 


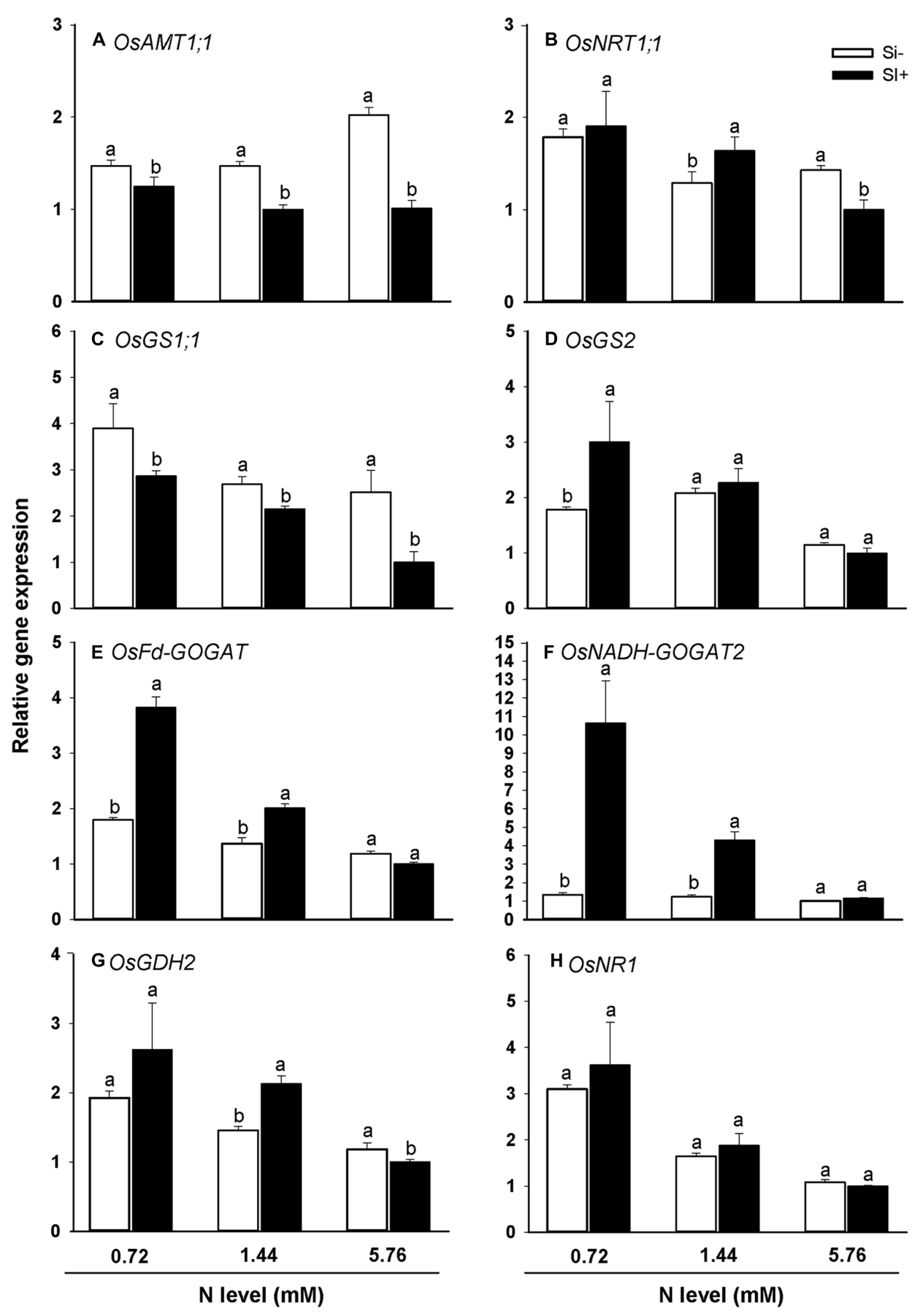

FIGURE 5 | Effects of Si amendment on the relative expression of genes involved in $\mathbf{N}$ uptake (A) OsAMT1;1 and (B) OsNRT1;1 and assimilation (C) OsGS1;1, (D) OsGS2, (E) OsFd-GOGAT, (F) OsNADH-GOGAT2, (G) OsGDH2, and (H) OsNR1 in rice plants. Values are mean \pm SE ( $n=3)$. Letters above bars indicate significant differences among treatments (Tukey's multiple range test, $P<0.05$ ).

an interaction between $\mathrm{N}$ and $\mathrm{Si}$ accumulation in rice plants, which in most cases appears to be mutually antagonistic. While we have provided, preliminary data describing some molecular details of these interactions, much more work will be required to fully elucidate the regulatory mechanisms involved.
Nutrient status not only influences plant growth rates, but also effects the defensive capabilities of plants (Ishiguro, 2001; Altieri and Nicholls, 2003), therefore interactions between $\mathrm{N}$ and $\mathrm{Si}$ in rice may have important consequences for plant-insect herbivore interactions. High $\mathrm{N}$ fertilization levels increased the honeydew excretion of BPH (Figure 6A), suggesting that high 

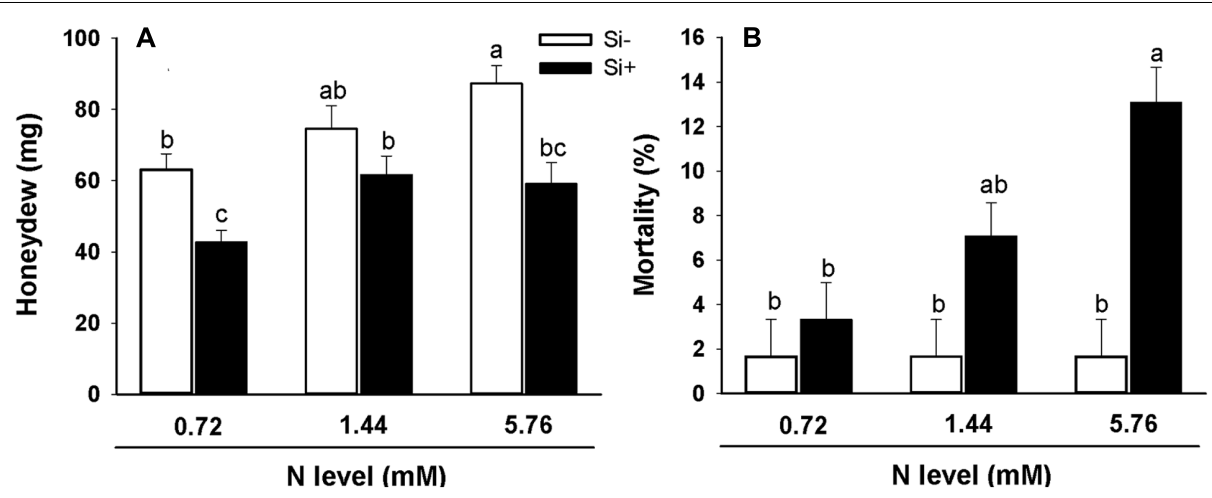

FIGURE 6 | Honeydew production (A) and percent mortality (B) of BPH feeding on rice plants fertilized at different $\mathrm{N}$ levels (0.72, 1.44 , and 5.76 mM), with or without Si amendment (Si-, Si+). Values are mean \pm SE $(n=20)$. Letters above bars indicate significant differences among treatments (Tukey's multiple range test, $P<0.05)$.

$\mathrm{N}$ input may increase the risk of $\mathrm{BPH}$ infestation in rice plants. Various inhibitory effects of $\mathrm{Si}$ on insect herbivore infestations have been documented by prior studies, including reports of increased survival rates and increased stalk damage with stalk borer infestations in sugarcane grown under elevated $\mathrm{N}$ levels, while Si amendment reduced stalk damage (Keeping et al., 2014). In our work, Si treatment effectively reduced the $\mathrm{BPH}$ honeydew excretion in the rice plants, and additionally in high $\mathrm{N}$-fertilized rice, the mortality of $\mathrm{BPH}$ feeding on Si-treated plants was significantly increased relative to Si-untreated plants (Figures 6A,B).

An increased physical barrier produced by $\mathrm{Si}$ deposition beneath leaf cuticles has long been considered as a major mechanism underlying Si-mediated plant resistance to insect pests (Reynolds et al., 2009). Silicon deposition, occurring mainly as amorphous silica in the form of phytoliths in the epidermis (Currie and Perry, 2007), increases the rigidity and abrasiveness of plant tissues, thereby creating a mechanical barrier and reducing their digestibility to insect herbivores (Goussain et al., 2005; Kvedaras et al., 2007; Massey and Hartley, 2009). Recent studies have demonstrated that Si-mediated antiherbivore defense is inducible and chemically mediated (Gomes et al., 2005; Kvedaras et al., 2010; Ye et al., 2013).

It is well-known that the salicylic acid (SA) and jasmonic acid (JA) signaling pathways play vital roles in plant chemical defense responses, and phloem-feeding insects like $\mathrm{BPH}$ tend to induce SA-mediated plant anti-herbivore defense, and NPR1 represents the major regulatory gene involved in SA signaling pathway (Moran and Thompson, 2001; Wasternack and Hause, 2013). MAPK cascades are involved in the transduction of various stimuli, including abiotic and biotic stressors, and MPK3 and MPK6 act as positive mediators of defense responses in plants (Takahashi et al., 2007; Pitzschke et al., 2009). In the present work, we also found that $\mathrm{BPH}$ infestation significantly increased the expression of OsNPR1, OsMPK3, and OsMPK6 in both Si-treated and untreated plants following $\mathrm{BPH}$ inoculation (Figure 7). Our previous work showed that SA levels in $\mathrm{BPH}$-infested rice were significantly higher than those in the non-infested plants (Ye et al., 2012), suggesting that SA-mediated defense responses can be induced by $\mathrm{BPH}$ in rice. More work should be conducted to confirm the detailed mechanisms involved. In Si-untreated plants, OsNPR1 and OsMPK3 transcript levels were much higher under low $\mathrm{N}$ fertilization $(0.72$ and $1.44 \mathrm{mM})$ than transcript levels observed under high $\mathrm{N}$ fertilization $(5.76 \mathrm{mM})$ at 4 h post$\mathrm{BPH}$ inoculation, indicating that rice plants may responded more rapidly to $\mathrm{BPH}$ infestation under lower $\mathrm{N}$ in by up-regulation of OsNPR1 and OsMPK3 genes. The different expression pattern between $O s M P K 3$ and OsMPK6 in response to $\mathrm{BPH}$ infestation (Figures 7B,C) indicates that the two MAPKS may be mediated independently by different signaling pathways in rice response to $\mathrm{BPH}$, and defense strategies are likely to be quite complicated. At high $\mathrm{N}$ fertilization level, Si amendment significantly increased NPR1 and MPK3 transcript level relative to Si-untreated plants after $\mathrm{BPH}$ inoculation at 4 and $8 \mathrm{~h}$ (Figures 7A,B), suggesting that in addition to physical barrier, $\mathrm{Si}$-mediated rice resistance to $\mathrm{BPH}$ is also inducible and much possibly SA-mediated.

\section{CONCLUSION}

Our results show that an interaction exists between $\mathrm{N}$ and $\mathrm{Si}$ in rice. High $\mathrm{N}$ fertilization levels lead to reduced $\mathrm{Si}$ accumulation, due likely to decreased expression of OsLsi1 and OsLsi2, which are the major transporters responsible for Si uptake and transport in rice. Our results also suggest that OsAMT1;1 and OsGS1;1 may play an important role in Simediated inhibition of $\mathrm{N}$ accumulation in rice, since transcript levels for both genes were significantly reduced in Si-treated plants relative to $\mathrm{Si}$-untreated plants at all $\mathrm{N}$ fertilization levels tested. At lower $\mathrm{N}$ fertilization levels, Si treatment tended to increase the transcript levels of certain genes involved in $\mathrm{N}$ uptake and assimilation, potentially identifying a feedback response mechanism operating under reduced $\mathrm{N}$ availability. $\mathrm{Si}$ amendment also enhanced rice resistance to $\mathrm{BPH}$, thus the strong interaction between $\mathrm{Si}$ and $\mathrm{N}$ accumulation in rice may have important implications for the resistance of rice plants to insect herbivores when grown in the presence of high $\mathrm{N}$ or Si-amended soils. 


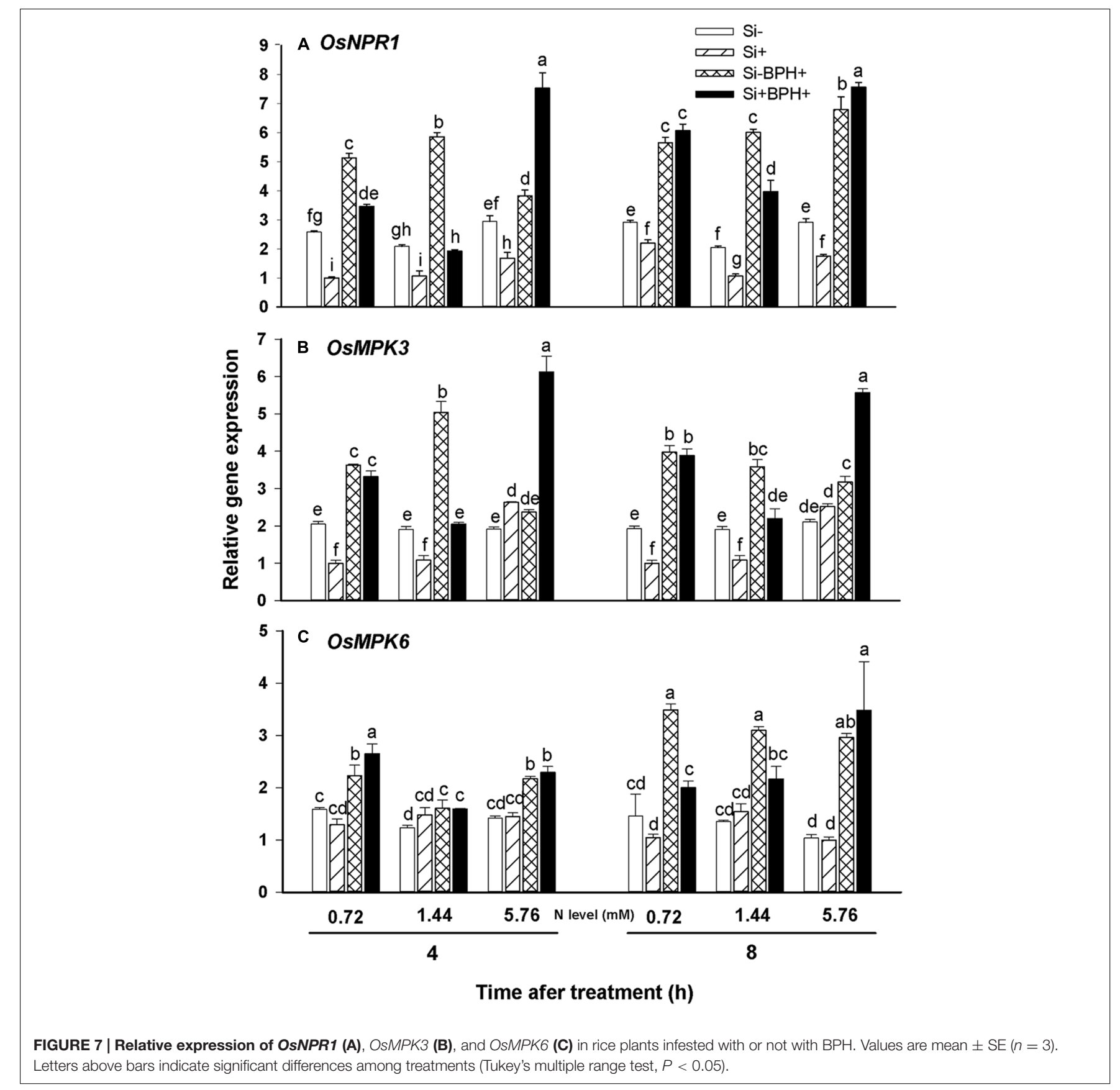

\section{AUTHOR CONTRIBUTIONS}

$\mathrm{XW}$ and RZ designed the research; XW, YY, GL, YS, $\mathrm{CD}$, and JN performed the research; XW, YS, SB, ZP, and RZ analyzed data; XW, SB, ZP, and RZ wrote the manuscript.

\section{ACKNOWLEDGMENTS}

This research was supported by the Natural Science Foundation of Guangdong Province of China (Grant No. 2014A030310227),
China Postdoctoral Science Foundation (2014M552208), Natural Science Foundation of China $(31670414,31470477)$, One Hundred Talents Program of Fujian Province of China (2014) and Talent Program of Fujian Agriculture and Forestry University.

\section{SUPPLEMENTARY MATERIAL}

The Supplementary Material for this article can be found online at: http://journal.frontiersin.org/article/10.3389/fpls.2017.00028/ full\#supplementary-material 


\section{REFERENCES}

Altieri, M. A., and Nicholls, C. I. (2003). Soil fertility management and insect pests: harmonizing soil and plant health in agroecosystems. Soil. Till. Res. 72, 203-211. doi: 10.1016/S0167-1987(03)00089-8

Awmack, C. S., and Leather, S. R. (2002). Host plant quality and fecundity in herbivorous insects. Annu. Rev. Entomol. 47, 817-844. doi: 10.1146/annurev. ento.47.091201.145300

Bottrell, D. G., and Schoenly, K. G. (2012). Resurrecting the ghost of green revolutions past: the brown planthopper as a recurring threat to high-yielding rice production in tropical Asia. J. Asia Pac. Entomol. 15, 122-140. doi: 10.1016/ j.aspen.2011.09.004

Brodbeck, B., Stavisky, J., Funderburk, J., Andersen, P., and Olson, S. (2001). Flower nitrogen status and populations of Frankliniella occidentalis feeding on Lycopersicon esculentum. Entomol. Exp. Appl. 99, 165-172. doi: 10.1673/031. 011.0141

Chen, Y., Olson, D. M., and Ruberson, J. R. (2010). Effects of nitrogen fertilization on tritrophic interactions. Arthropod Plant Inte. 4, 81-94. doi: 10.1111/17447917.12123

Chen, Y., Ruberson, J. R., and Olson, D. M. (2008). Nitrogen fertilization rate affects feeding, larval performance, and oviposition preference of the beet armyworm, Spodoptera exigua, on cotton. Entomol. Exp. Appl. 126, 244-255. doi: 10.1111/j.1570-7458.2007.00662.x

Comadira, G., Rasool, B., Karpinska, B., Morris, J. A., Verrall, S. R., and Hedley, P. E. (2015). Nitrogen deficiency in barley (Hordeum vulgare) seedlings induces molecular and metabolic adjustments that trigger aphid resistance. J. Exp. Bot. 66, 3639-3655. doi: 10.1093/jxb/erv276

Currie, H. A., and Perry, C. C. (2007). Silica in plants: biological, biochemical and chemical studies. Ann. Bot. 100, 1383-1389. doi: 10.1093/aob/mcm247

Dannon, E. A., and Wydra, K. (2004). Interaction between silicon amendment, bacterial wilt development and phenotype of Ralstonia solanacearum in tomato genotypes. Physiol. Mol. Plant Pathol. 64, 233-243. doi: 10.1016/j.pmpp.2004. 09.006

De Kraker, J., Rabbinge, R., Huis, A. V., van Lenteren, J. C., and Heong, K. L. (2000). Impact of nitrogenous-fertilization on the population dynamics and natural control of rice leaf folder (Lep.: Pyralidae). Int. J. Pest. Manag. 46, 225-235. doi: 10.1080/096708700415571

Deren, C. W. (1997). Changes in nitrogen and phosphorus concentrations on silicon-fertilized rice grown on organic soil. J. Plant Nutr. 20, 765-771. doi: $10.1080 / 01904169709365292$

Epstein, E. (1999). Silicon. Annu. Rev. Plant Physiol. Plant. Mol. Biol. 50, 641-664. doi: 10.1146/annurev.arplant.50.1.641

Ericsson, T. (1995). Growth and shoot: root ratio of seedlings in relation to nutrient availability. Plant Soil. 168, 205-214. doi: 10.1007/BF00029330

Fauteux, F., Chain, F., Belzile, F., Menzies, J. G., and Bélanger, R. R. (2006). The protective role of silicon in the Arabidopsis-powdery mildew pathosystem. Proc. Natl. Acad. Sci. U.S.A. 103, 17554-17559. doi: 10.1073/pnas.0606330103

Fawe, A., Abou-Zaid, M., Menzies, J. G., and Bélanger, R. R. (1998). Siliconmediated accumulation flavonoid phytoalexins cucumber. Phytopathology 88 396-401. doi: 10.1094/PHYTO.1998.88.5.396

Gomes, F. B., Moraes, J. C., Santos, C. D., and Goussain, M. M. (2005). Resistance induction in wheat plants by silicon and aphids. Sci. Agric. 62, 547-551. doi: 10.1603/EN13234

Goussain, M. M., Prado, E., and Moraes, J. C. (2005). Effect of silicon applied to wheat plants on the biology and probing behaviour of the greenbug Schizaphis graminum (Rond.) (Hemiptera: Aphidiae). Neotrop. Entomol. 34, 807-813. doi: 10.1590/S1519-566X2005000500013

He, W. Q., Yang, M., Li, Z. H., Qiu, J. L., Liu, F., Qu, X. S., et al. (2015). High levels of silicon provided as nutrient in hydroponic culture enhances rice plant resistance to brown planthopper. Crop Prot. 67, 20-25. doi: 10.1016/j.cropro. 2014.09.013

Ishiguro, K. (2001). Improving management strategy for rice blast disease using a simulation model of rice leaf blast epidemics. Bull. Tohoku. Natl. Agric. Exp. Stn. 99, 1-110.

Keeping, M. G., and Meyer, J. H. (2006). Silicon-mediated resistance of sugarcane to Eldana saccharina Walker (Lepidoptera: Pyralidae): effects of silicon source and cultivar. J. Appl. Entomol. 130, 410-420. doi: 10.1111/j.1439-0418.2006. 01081.x
Keeping, M. G., Miles, N., and Sewpersad, C. (2014). Silicon reduces impact of plant nitrogen in promoting stalk borer (Eldana saccharina) but not sugarcane thrips (Fulmekiola serrata) infestations in sugarcane. Front. Plant Sci. 5:289. doi: 10.3389/fpls.2014.00289

Khan, M., and Port, G. (2008). Performance of clones and morphs of two cereal aphids on wheat plants with high and low nitrogen content. Entomol. Sci. 11, 159-165. doi: 10.1111/j.1479-8298.2008.00262.x

Kvedaras, O. L., An, M., Choi, Y. S., and Gurr, G. M. (2010). Silicon enhances natural enemy attraction and biological control through induced plant defences. Bull. Entomol. Res. 100, 367-371. doi: 10.1017/S0007485309990265

Kvedaras, O. L., Keeping, M. G., Goebel, F. R., and Byrne, M. J. (2007). Larval performance of the pyralid borer Eldana saccharina walker and stalk damage in sugarcane: influence of plant silicon, cultivar and feeding site. Int. J. Pest. Manag. 53, 183-194. doi: 10.1080/09670870601110956

Lemus, R., Brummer, E. C., Burras, C. L., Moore, K. J., Barker, M. F., and Molstad, N. E. (2008). Effects of nitrogen fertilization on biomass yield and quality in large fields of established switchgrass in southern Iowa, USA. Biom. Bioenergy 32, 1187-1194. doi: 10.1016/j.biombioe.2008.02.016

Lu, Z. X., Heong, K. L., Yu, X. P., and Hu, C. (2005). Effects of nitrogen on the tolerance of brown planthopper, Nilaparvata lugens, to adverse environmental factors. Insect Sci. 12, 121-128. doi: 10.1111/j.1744-7917.2005.00014.x

Lu, Z. X., Yu, X. P., Heong, K. L., and Hu, C. (2007). Effect of nitrogen fertilizer on herbivores and its stimulation to major insect pests in rice. Rice Sci. 14, 56-66. doi: 10.1016/S1672-6308(07)60009-2

Ma, J. F., and Yamaji, N. (2006). Silicon uptake and accumulation in higher plants. Trends Plant Sci. 11, 392-397. doi: 10.1016/j.tplants.2006.06.007

Ma, J. F., and Yamaji, N. (2008). Functions and transport of silicon in plants. Cell Mol. Life Sci. 65, 3049-3057. doi: 10.1007/s00018-008-7580-x

Massey, F. P., Ennos, A. R., and Hartley, S. E. (2007). Herbivore specific induction of silica-based plant defences. Oecologia 152, 677-683. doi: 10.1007/s00442007-0703-5

Massey, F. P., and Hartley, S. E. (2009). Physical defences wear you down progressive and irreversible impacts of silica on insect herbivores. J. Anim. Ecol. 78, 281-291. doi: 10.1111/j.1365-2656.2008.01472.x

Mattson, W. J. Jr. (1980). Herbivory in relation to plant nitrogen content. Annu. Rev. Ecol. Syst. 11, 119-161. doi: 10.1146/annurev.es.11.110180.001003

Mauad, M., Crusciol, C. A. C., Grassi Filho, H., and Rodrigues Machado, S. (2013). Silica deposition and rate the nitrogen is silicon in rice. Semin Cienc. Agrar. 34, 1653-1661.

Mauad, M., Grassi, H., and Crusciol, C. A. C. (2003). Silicon contents in soil and in highland rice plants under different doses of silicon and nitrogen fertilization. Rev. Bras. Cienc. Solo. 27, 867-873. doi: 10.1590/S0100-06832003000500011

Meharg, C., and Meharg, A. A. (2015). Silicon, the silver bullet for mitigating biotic and abiotic stress, and improving grain quality, in rice? Environ. Exp. Bot. 120, 8-17. doi: 10.1016/j.envexpbot.2015.07.001

Moon, C. E., Lewis, B. E., Murray, L., and Sanderson, S. M. (1995). Russian wheat aphid (Homoptera: Aphididae) development, reproduction, and longevity on hydroponically grown wheat with varying nitrogen levels. Environ. Entomol. 24, 367-371. doi: 10.1093/ee/24.2.367

Moran, P. J., and Thompson, G. A. (2001). Molecular response to aphid feeding in Arabidopsis in relation to plant defense pathways. Plant. Physiol. 125, 1074-1085. doi: 10.1104/pp.125.2.1074

Novozamsky, I., Van Eck, R., and Houba, V. J. G. (1984). A rapid determination of silicon in plant material. Commun. Soil Sci. Plant Anal. 15, 205-211. doi: $10.1080 / 00103628409367470$

Pitzschke, A., Schikora, A., and Hirt, H. (2009). MAPK cascade signaling networks in plant defence. Curr. Opin. Plant Biol. 12, 1-6. doi: 10.1016/j.pbi.2009. 06.008

Rennenberg, H., Wildhagen, H., and Ehlting, B. (2010). Nitrogen nutrition of poplar trees. Plant Biol. 12, 275-291. doi: 10.1111/j.1438-8677.2009.00309.x

Reynolds, O. L., Keeping, M. G., and Meyer, J. H. (2009). Silicon-augmented resistance of plants to herbivorous insects: a review. Ann. Appl. Biol. 155, 171-186. doi: 10.1111/j.1744-7348.2009.00348.x

Slansky, F. (1990). Insect nutritional ecology as a basis for studying host plant resistance. Florida Entomol. 73, 354-378. doi: 10.2307/3495455

Tabuchi, M., Abiko, T., and Yamaya, T. (2007). Assimilation of ammonium ions and reutilization of nitrogen in rice (Oryza sativa L.). J. Exp. Bot. 58, 2319-2327. doi: $10.1093 / \mathrm{jxb} / \mathrm{erm} 016$ 
Takahashi, F., Yoshida, R., Ichimura, K., Mizoguchi, T., Seo, S., Yonezawa, M., et al. (2007). The mitogen-activated protein kinase cascade MKK3-MPK6 is an important part of jasmonate signal transduction pathway in Arabidopsis. Plant Cell 19, 805-818. doi: 10.1105/tpc.106.046581

Tsujimoto, Y., Muranaka, S., Saito, K., and Asai, H. (2014). Limited Sinutrient status of rice plants in relation to plant-available $\mathrm{Si}$ of soil, nitrogen fertilizer application, and rice-growing environments across Sub-Saharan Africa. Filed Crop Res. 155, 1-9. doi: 10.1016/j.fcr.2013. 10.003

Wasternack, C., and Hause, B. (2013). Jasmonates: biosynthesis, perception, signal transduction and action in plant stress response, growth and development. An update to the 2007 review in annals of botany. Ann. Bot. 111, 1021-1058. doi: $10.1093 / \mathrm{aob} / \mathrm{mct} 067$

Winter, T. R., and Rostás, M. (2010). Nitrogen deficiency affects bottom-up cascade without disrupting indirect plant defense. J. Chem. Ecol. 36, 642-651. doi: 10.1007/s10886-010-9797-z

Yamaji, N., Mitatni, N., and Ma, J. F. (2008). A transporter regulating silicon distribution in rice shoots. Plant Cell 20, 1381-1389. doi: 10.1105/tpc.108. 059311
Ye, M., Luo, S. M., Xie, J. F., Li, Y. F., Xu, T., Liu, Y., et al. (2012). Silencing COI1 in rice increases susceptibility to chewing insects and impairs inducible defense. PLoS ONE 4:e36214. doi: 10.1371/journal.pone.0036214

Ye, M., Song, Y. Y., Long, J., Wang, R. L., Baerson, S. R., Pan, Z. Q., et al. (2013). Priming of jasmonate-mediated antiherbivore defense responses in rice by silicon. Proc. Natl. Acad. Sci. U.S.A. 110, 3631-3639. doi: 10.1073/pnas. 1305848110

Conflict of Interest Statement: The authors declare that the research was conducted in the absence of any commercial or financial relationships that could be construed as a potential conflict of interest.

Copyright (C) 2017 Wu, Yu, Baerson, Song, Liang, Ding, Niu, Pan and Zeng. This is an open-access article distributed under the terms of the Creative Commons Attribution License (CC BY). The use, distribution or reproduction in other forums is permitted, provided the original author(s) or licensor are credited and that the original publication in this journal is cited, in accordance with accepted academic practice. No use, distribution or reproduction is permitted which does not comply with these terms. 